\title{
Evaluation and Significance of MIB-1 Labelling Index in Grading of Diffuse Gliomas
}

\author{
Dr. Sangeeta Yadav $^{1 *}$, Dr. Surabhi Tyagi ${ }^{2}$, Dr. B. S. Sharma ${ }^{3}$
}

3rd Yr. P.G Student, Mahatma Gandhi Medical College, Jaipur, Tonk Rd, near India International School, Ricco Industrial Area, Sitapura, Jaipur, Rajasthan 302022, India

${ }^{2}$ Professor Neuropathology, Mahatma Gandhi Medical College, Jaipur, Tonk Rd, near India International School, Ricco Industrial Area, Sitapura, Jaipur, Rajasthan 302022, India

${ }^{3}$ Professor \& HOD Neurosurgery, Mahatma Gandhi Medical College, Jaipur, Tonk Rd, near India International School, Ricco Industrial Area, Sitapura, Jaipur, Rajasthan 302022, India

DOI: $10.36347 /$ sjams.2020.v08i05.033

| Received: 20.01.2020 | Accepted: 27.01.2020 | Published: 27.05.2020

*Corresponding author: Dr. Sangeeta Yadav

\section{Abstract}

\section{Original Research Article}

Aims \& objectives: Tumor grading is a significant predictor for clinical outcome of diffuse gliomas. It affects the treatment and prognosis of the patient. The aim of the present study is evaluation of MIB-1 labelling index (LI) in grading diffuse gliomas. Material \& Methods: Our study included 50 cases which were diagnosed as diffuse gliomas on H\&E staining. Then immunohistochemistry was done for evaluation of MIB-1 labelling index. Grading of tumor was done according to 2016 World Health Organization classification. Result: On H\&E, out of 50 cases 17 were diffuse astrocytomas, 4 anaplastic astrocytomas, 18 glioblastomas, 4 oligodendrogliomas and 7 anaplastic oligodendrogliomas cases were diagnosed on $\mathrm{H} \& \mathrm{E}$ examination. Then IHC was done for the evaluation of MIB1 labelling index and it was found that, out of 17 diffuse astrocytomas, 4 were upgraded to anaplastic astrocytomas and out of 4 oligodendrogliomas, 2 were upgraded in higher grade anaplastic oligodendrogliomas because of increased MIB1. Conclusion: MIB-1Labelling index is used as an effective tool in assessing proliferative index in diffuse gliomas and also as an important prognostic indicator supplementing the standard histopathological assessment. Present study demonstrates the usefulness of MIB-1 labelling index in diffuse gliomas for accuracy of grading the tumor. Exact grading is important for treatment and affects the prognosis of the patient.

Keywords: Diffuse glioma, astrocytoma; MIB-1 Labelling index; tumor grade, oligodendroglioma.

Copyright @ 2020: This is an open-access article distributed under the terms of the Creative Commons Attribution license which permits unrestricted use, distribution, and reproduction in any medium for non-commercial use (NonCommercial, or CC-BY-NC) provided the original author and source are credited.

\section{Material And Methods}

This study is a hospital based study. A total of fifty cases diagnosed as diffuse gliomas on $\mathrm{H} \& \mathrm{E}$ between January 2018 to June 2019 were included in this study. IHC was done on all the cases for evaluation of MIB1 and tumors were graded using the 2016 WHO classification [1].

\section{Place of study}

This study was carried out in Department of Pathology, Mahatma Gandhi Medical College and hospital, Sitapura, Jaipur, Rajasthan.

\footnotetext{
No. of case 50

Approvals

Institutional ethical committee approval is obtained prior to study.
}

Written and informed consent was obtained from all the participants before enrolment into the study.

All neuropathological specimens of gliomas received were analysed with respect to gross and microscopic features. All specimens fixed in $10 \%$ formalin and the entire brain tumor tissue specimen sent processed as per standard guidelines.

After routine paraffin processing sections were routinely stained with haematoxylin and eosin stain.

All the cases were evaluated under $\mathrm{H} \& \mathrm{E}$ first and then followed by IHC.

IHC was carried out at least on one representative block in all the cases. IHC was performed using primary antibody for MIB1. MIB1 proliferation index was determined by counting 10 high 
power fields $(400 \times$ magnification) at the highest proliferating area and was expressed in percentage.

\section{Inclusion Criteria}

- 50 Tumor tissues received \& diagnosed on $\mathrm{H}$ $\& \mathrm{E}$ as diffuse gliomas were included in the study.

\section{Exclusion Criteria}

- Improperly fixed specimen.

- Autolysed tissues.

\section{RESULTS}

Detailed microscopic examination of the tissue was done by the experienced pathologist to arrive at the Histopathological diagnosis.
Immunohistochemical stains were performed by using formalin fixed paraffin sections of 50 cases with MIB1 and evaluated.

On H\&E, out of 50 cases 17 were diffuse astrocytomas, 4 anaplastic astrocytomas, 18 glioblastomas, 4 oligodendrogliomas and 7 anaplastic oligodendrogliomas cases were diagnosed on $\mathrm{H} \& \mathrm{E}$ examination. Then IHC was done for the evaluation of MIB1 labelling index and it was found that, out of 17 diffuse astrocytomas ,4 were upgraded to anaplastic astrocytomas and out of 4 oligodendrogliomas, 2 were upgraded in higher grade anaplastic oligodendrogliomas because of increased MIB1.

Table-1: Distribution of tumours according to HPE

\begin{tabular}{|l|l|l|}
\hline Histo-pathogical type & Frequency & Percent \\
\hline Diffuse Astrocytoma Grade II & 17 & 34.00 \\
\hline Anaplastic Astrocytoma Grade III & 4 & 8.00 \\
\hline Glioblastoma Grade IV & 18 & 36.00 \\
\hline Oligodendroglioma Grade II & 4 & 8.00 \\
\hline Anaplastic Oligodendoglioma Grade III & 7 & 14.00 \\
\hline Total & 50 & 100.00 \\
\hline
\end{tabular}

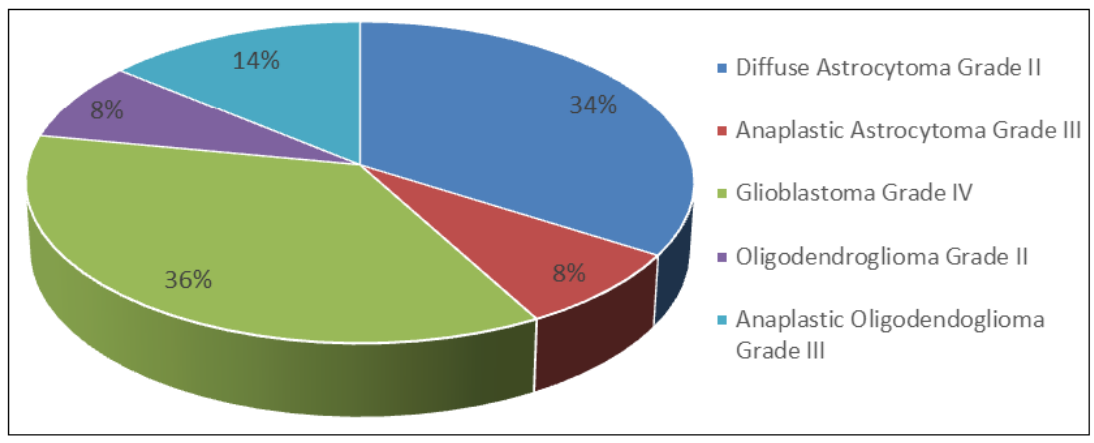

Fig-1: Distribution of tumours according to HPE

Out of 50 cases of diffuse gliomas maximum were glioblastomas (WHO grade IV) 36\% followed by diffuse astrocytoma (WHO grade II) (34\%).

Table-2: Cross tabulation of HPE subtype and diagnosis by MIB1

\begin{tabular}{|c|c|c|c|c|c|c|}
\hline \multirow[t]{2}{*}{ HPE Subtype } & \multicolumn{5}{|c|}{ Diagnosis by MIB1 } & \multirow[t]{2}{*}{ Total } \\
\hline & $\begin{array}{l}\text { Diffuse } \\
\text { Astrocytom } \\
\text { a Grade II } \\
\end{array}$ & $\begin{array}{l}\text { Anaplastic } \\
\text { Astrocytoma } \\
\text { Grade III } \\
\end{array}$ & $\begin{array}{l}\text { Oligodendroglio } \\
\text { ma Grade II }\end{array}$ & $\begin{array}{l}\text { Anaplastic } \\
\text { Oligodendoglio } \\
\text { ma Grade III } \\
\end{array}$ & $\begin{array}{l}\text { Glioblastom } \\
\text { a Grade IV }\end{array}$ & \\
\hline $\begin{array}{ll}\text { Diffuse } & \text { Astrocytoma } \\
\text { Grade II } & \\
\end{array}$ & $13(26.00)$ & $4(8.00)$ & $0(0.00)$ & $0(0.00)$ & $0(0.00)$ & $17(34.00)$ \\
\hline $\begin{array}{l}\text { Anaplastic } \\
\text { Astrocytoma Grade III }\end{array}$ & $0(0.00)$ & $4(8.00)$ & $0(0.00)$ & $0(0.00)$ & $0(0.00)$ & $4(8.00)$ \\
\hline $\begin{array}{l}\text { Oligodendroglioma } \\
\text { Grade II }\end{array}$ & $0(0.00)$ & $0(0.00)$ & $2(4.00)$ & $2(4.00)$ & $0(0.00)$ & $4(8.00)$ \\
\hline $\begin{array}{l}\text { Anaplastic } \\
\text { Oligodendoglioma } \\
\text { Grade III }\end{array}$ & $0(0.00)$ & $0(0.00)$ & $0(0.00)$ & $6(12.00)$ & $1(2.00)$ & $7(14.00)$ \\
\hline $\begin{array}{l}\text { Glioblastoma Grade } \\
\text { IV }\end{array}$ & $0(0.00)$ & $0(0.00)$ & $0(0.00)$ & $0(0.00)$ & $18(36.00)$ & $18(36.00)$ \\
\hline Total & $13(26.00)$ & $8(16.00)$ & $2(4.00)$ & $8(16.00)$ & $19(38.00)$ & $50(100.00)$ \\
\hline
\end{tabular}


Out of 17 diffuse astrocytomas (WHO grade II), 4 were upgraded to anaplastic astrocytomas (WHO grade III) because of increased MIB1. Out of 4 oligodendrogliomas (WHO grade II), 2 were upgraded in higher grade anaplastic oligodendrogliomas (WHO grade III).

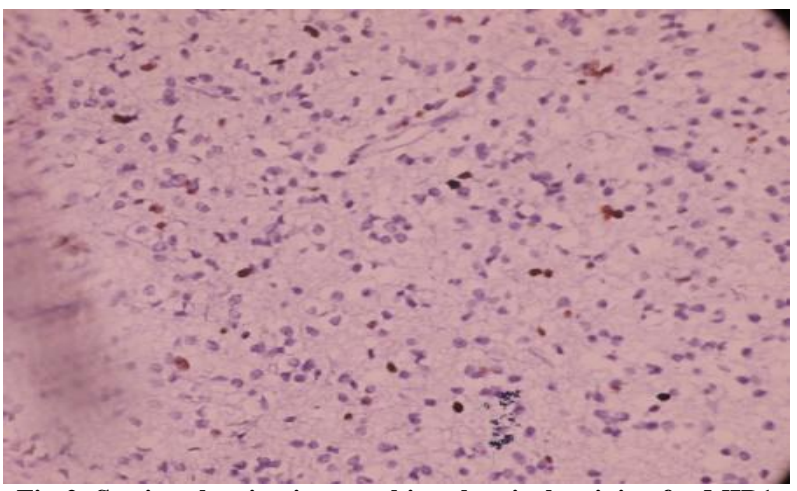

Fig-2: Section showing immunohistochemical staining for MIB1 in anaplastic astrocytoma (WHO grade III) (40X)

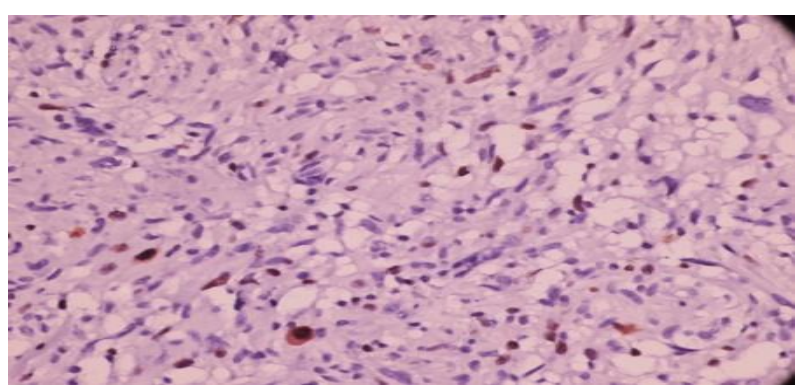

Fig-3: Section showing immunohistochemical staining for MIB1 in glioblastoma (WHO grade IV) (40X)

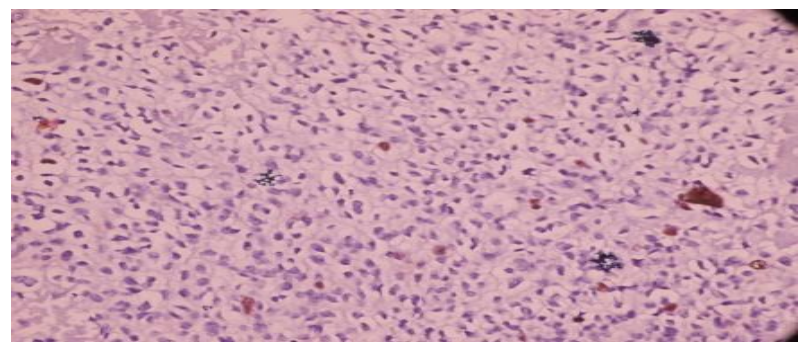

Fig-4: Section showing immunohistochemical staining for MIB1 in anaplastic oligodendroglioma (WHO grade III) (40X)

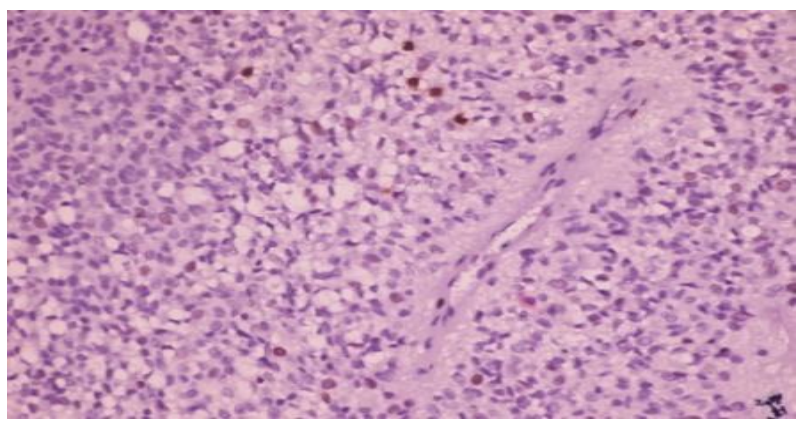

Fig-5: Section showing immunohistochemical staining for MIB1 in oligodendroglioma (WHO grade II) $(40 \mathrm{X})$

\section{DISCUSSION}

The World Health Organization (WHO) 2016 classification of central nervous system (CNS) tumors represents a paradigm shift from the previous classifications, as, for the first time, the definition of diffuse gliomas is based on both histological and molecular alterations [1]. It also highlights the role of MIB1 in evaluation of proliferation rates and exact grading of the tumor.

Immunohistochemical determination of proliferative activity is a useful supplement for establishing the histopathological diagnosis of diffuse gliomas. Ki-67/MIB-1 immunostaining is most commonly used and has been shown to correlate positively with tumor grade and prognosis $[2,3]$.

MIB-1 Labelling index was done to assess the proliferative activity in diffuse gliomas. It also helps in cases where it is sometimes difficult to grade based on morphology and marginally increased mitosis alone to grade the tumor. As per WHO classification grading is based on MIB1 index rather than mitosis alone.

Various studies have shown that evaluation of MIB 1 leads to increasing the grade of the tumor from low to higher grade, there by affecting its treatment and prognosis. The treatment of low grade and high grade tumors is different involving radiotherapy and adjuvant chemotherapy.

In our study, the reports demonstrated that out of 17 diffuse astrocytomas, 4 were upgraded to anaplastic astrocytomas (WHO grade III) and out of 4 oligodendrogliomas (WHO grade II), 2 were upgraded to anaplastic oligodendrogliomas (WHO grade III).

Johannessen et al in 2006 [4] analysed and reviewed 16 studies which constituted a total of 915 patients demonstrating a substantial increase in MIB-1 Labelling index with increasing grade of malignancy.

\section{CONCLUSION}

Histopathological diagnosis has been challenging to distinctly differentiate tumour either due to limited tissue availiblity or due to difficultly in identifying mitosis on Hematoxyllin and eosin stained sections. Therefore MIB-1 labelling index helps in exact evaluation and confirmation of grade of the tumor.

\section{REFERENCES}

1. Louis DN, Perry A, Reifenberger G, Von Deimling A, Figarella-Branger D, Cavenee WK, Ohgaki H, Wiestler OD, Kleihues P, Ellison DW. The 2016 World Health Organization classification of tumors of the central nervous 
system: a summary. Acta neuropathologica. 2016 Jun 1;131(6):803-20.

2. Takei H, Powell SZ. Novel immunohistochemical markers in the diagnosis of nonglial tumors of nervous system. Adv Anat Pathol. 2010;17:150153.

3. Prayson RA. The utility of MIB-1/Ki-67 immunostaining in the evaluation of central nervous system neoplasms. Adv Anat Pathol. 2005;12:144-148.
4. Johannessen AL, Torp SH. The clinical value of Ki-67/MIB-1 labeling index in human astrocytomas. Pathol Oncol Res. 2006;12:143-147.

5. Smith C, Ironside JW. Diagnosis and pathogenesis of gliomas. Current Diagnostic Pathology. 2007;13:180-192.

6. Trembath D, Miller CR, Perry A. Gray zones in brain tumor classification: evolving concepts. Adv Anat Pathol. 2008;15:287-297. 